\title{
AIR FORCE FLIGHT TEST INSTRUMENTATION SYSTEM
}

\author{
Michael F. Lamy \\ AFFTIS Proaram Technical Manager \\ SCI Systems, Inc. \\ Huntsville, Alabama
}

\begin{abstract}
In January, 1983 SCI Systems, Inc. initiated design under a contract with the U.S. Air Force for the development of the Air Force Flight Test Instrumentation System (AFFTIS). This system is being developed to provide for the flight test instrumentation needs of the Air Force through the 1990s.
\end{abstract}

The requirements specification was derived from the results of a survey conducted by the Air Force approximately two (2) years prior to contract award. The results of this survey were that the new system should provide more channels and higher frequencies, all in smaller size. In addition, the system should be modular and easily expandable to accommodate testing of yet undefined future aircraft systems. This paper describes the AFFTIS System as it is presently designed and some of the unique concepts used to meet the specified design goals.

\section{AIRBORNE SYSTEM DESIGN}

The Airborne PCM System utilizes a remote multiplex approach with a central control unit and some number of distributed data acquisition units. The central unit or AFFTIS System Controller (ASC) orchestrates the function of the PCM System via a high speed serial command/response data bus. Each of the remote data acquisition units (DAUs) includes a memory which contains format information. The command from the central controller (ASC) simply "points" to the correct format instruction location within the DAU.

\section{AFFTIS BUS}

The distributed nature of the AFFTIS system is depicted in Figure 1. The command/response bus, which carries commands from the ASC to the DAUs and the DAU data response to the ASC for PCM output is the AFFTIS bus. 


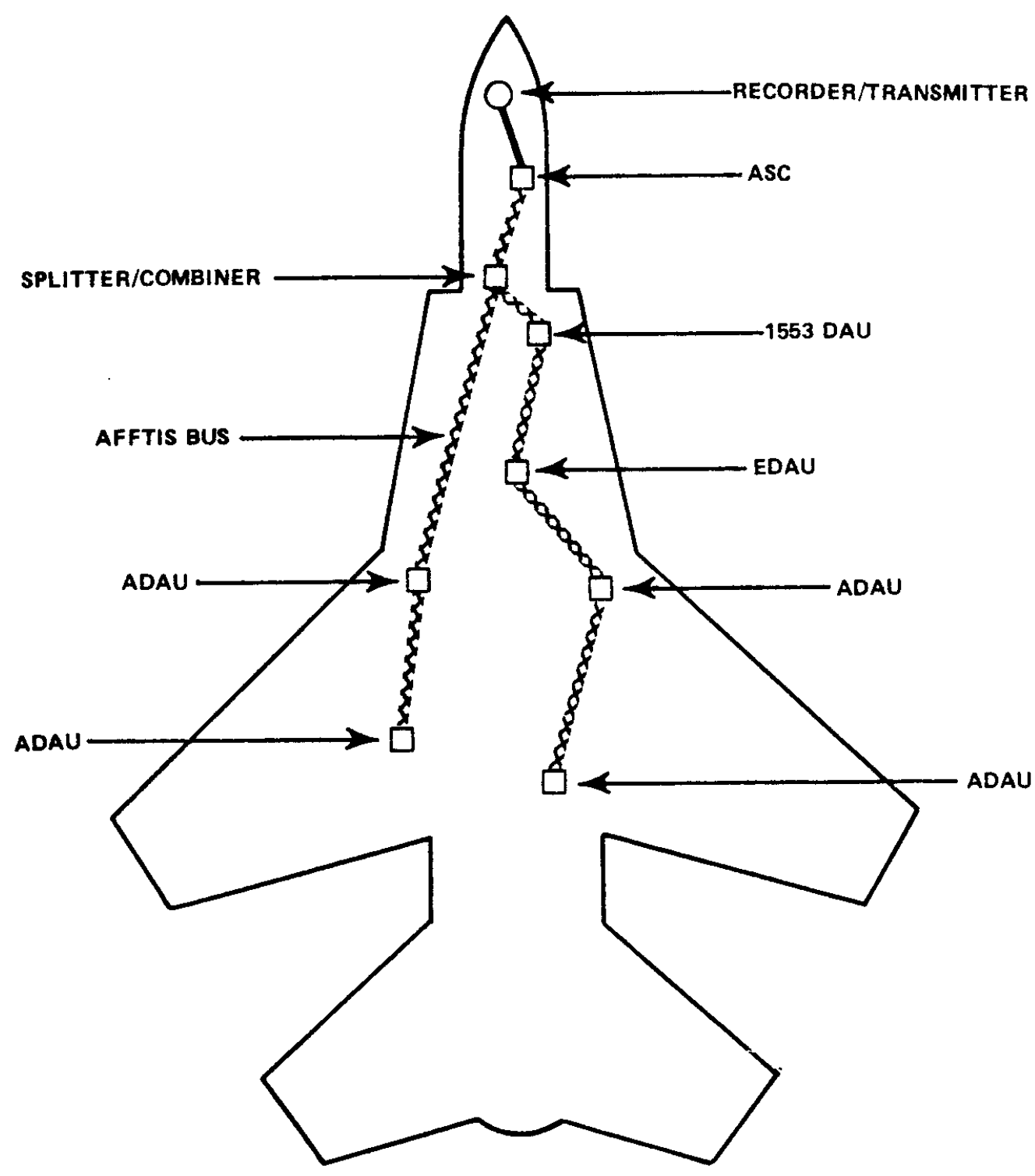

FIGURE 1

The AFFTIS bus is a 10 Megabit, full duplex serial bus. The bus consists of a command bus and a separate reply bus. All units are transformer coupled and connected in a "daisy chain" sequence. The command bus operates continuously at $10 \mathrm{Mbits} / \mathrm{sec}$ utilizing BiPhase-Space modulation. Each ASC to DAU command contains 20 bit times and occurs in synchronism with each PCM output word time. Any time on the command bus which exists between the end of a command and the beginning of the next PCM output word time is filled with filler bits.

This overall scheme offers several unique design advantages. First, the use of Bi-PhaseSpace modulation simplifies the generation and recovery of data. This is due in large part, to the fact that, as shown in Figure 2, each bit period begins and ends with a transition. As well as other advantages, this insures that, unlike 1553, the second sync waveform will 
always be 1.5 bit times wide. (The reader should recall that a MIL-STD-1553 bus uses BiPhase L modulation and that the first bit after sync can be a " 0 " thereby making the second sync waveform "appear" to be 2 bit times long.) Secondly, the command bus transmits continuously thereby allowing all of the remote units to "lock on" and synchronize with the ASC. As a result, all activities of the DAUs are synchronous and are supplied with a clock of the same accuracy as the ASC's master oscillator.

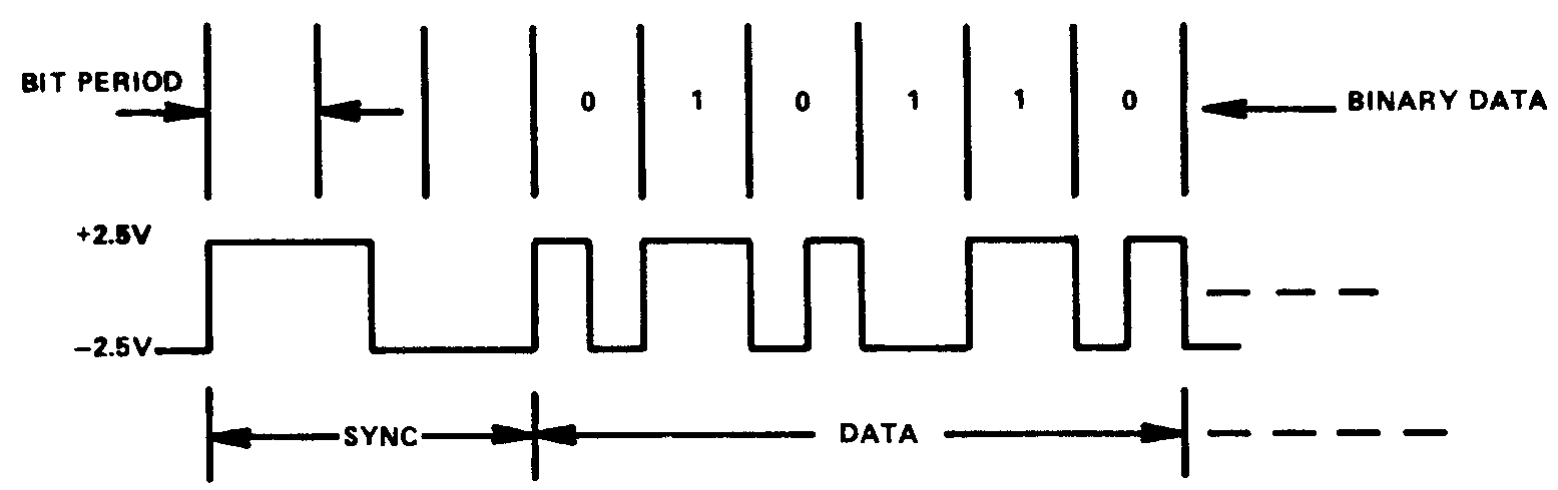

FIGURE 2

\section{AFFTIS SYSTEM CONTROLLER}

The ASC is the heart of the Airborne System and has been designed with a variety of features to provide the needed flexibility and capability to meet mission goals for the next 15 years.

All of the PCM format structure is user definable and programmable. The format commands are stored in a non-volatile EEPROM memory which can be altered electrically by the AFFTIS Ground Support Equipment. The characteristics of the ASC are:

$\begin{array}{lll}\text { Processor Type } & - & \text { AMD 29116 } \\ \text { Output Bit Rate } & - & \text { Class I - 10K to 5M Bits } \\ & \text { Class II - 100K to 40M Bits } \\ \text { PCM Word Length } & - & 10 / 12 / 14 / 16 \text { Bits, Programmable } \\ \text { Number of Formats } & - & 8 \text { Separately Programmable } \\ \text { Number of Words/Frame } & - & 2-256 / \text { Format } \\ \text { Subcommutation Rates } & - & 2-256 / \text { Format } \\ \text { Number of Subcoms } & - & \text { All Data Words } \\ \text { Number of Remote Units } & - & 64 \\ \text { Operating Temperature } & - & -54^{\circ} \mathrm{C} \text { to }+71^{\circ} \mathrm{C}\end{array}$




\section{ASC INTEGRAL DATA PROCESSOR}

The ASC includes the ability to perform real time data conversion to engineering units (EU). The EU conversion routines are user programmable with complete programming support provided via AFFTIS Ground Support Equipment. The resulting EU conversion may be displayed in flight as well as routed to PCM for output.

\section{ASC INTEGRAL TIME CODE GENERATOR}

A high performance IRIG Time Code Generator which may be externally synchronized is included as a part of the ASC. All functions are processor controlled with all outputs synthesized for maximum performance.

\section{ASC PROGRAMMABLE SECONDARY}

Secondary PCM outputs are provided for those applications where the tape recorder or telemetry transmitter does not have the bandwidth necessary to accommodate the primary PCM bit rate, or where the user wishes to partition the data into separate secondary outputs. There are two types of secondary PCM outputs provided:

Dedicated (max. of 8 outputs)

Programmable ( 2 independent outputs)

With the dedicated outputs, the primary PCM data is divided evenly at a correspondingly lower bit rate among the active secondary outputs. With the programmable outputs, the user is free to choose any of the primary PCM words to appear in each programmable secondary PCM output.

\section{DATA ACQUISITION UNITS}

The Data Acquisition Units (DAU) consist of two major types; the avionics data bus monitors and the Analog-Discrete Unit. The avionics bus monitor DAU allows the user to selectively capture data which may appear on an aircraft's avionics bus. The avionics bus DAUs under development include the MIL-STD-1553 DAU, (F-15) H009 DAU and ARINC DAU.

In each case, the DAU offers the user two methods of decommutating avionics bus data traffic. The first method utilizes standard techniques of capturing selected traffic and storing it in specified memory locations for later retrieval by the ASC. The second method utilizes a "ring buffer" mode. In this mode each specified item of avionics data traffic is stored in the next available "ring buffer". The result is that the message data integrity is 
maintained since all contiguous data is retrieved in proper temporal order. The characteristics of the Avionics Bus DAU are:

$\begin{array}{ll}\text { Processor Type } & - \text { AMD 29116 } \\ \text { Interfaces } & \text { - MIL-STD-1553/H009/ARINC } 429 \\ \text { Decom Mem Size } & -1020 \text { Words } \\ \text { Time Tag } & - \text { Tag all Words 20 Microsecond } \\ \text { Status } & - \text { Bus ID/Stale/Overflow } \\ \text { Operating } & --54^{\circ} \mathrm{C} \text { to }+71^{\circ} \mathrm{C}\end{array}$

\section{ANALOG-DISCRETE DAU}

The Analog-Discrete DAU or ADAU consiste of an "overhead" section as well as a signal conditioning section. The overhead section contains a 32 channel direct input analog multiplexer, a programmable gain amplifier, a 12 bit A/D converter and interface, a format memory and control circuitry. The signal conditioning area consists of six (6) general purpose signal conditioning card slots. These are designed to provide maximum user flexibility in signal conditioning selection by allowing any of the signal conditioning cards to operate in any slot.

The most difficult challenge of the ADAU design is to provide high sample rates (over $400 \mathrm{~K}$ ) while maintaining flexibility in channel and gain selection without undo sacrifice of accuracy. In order to accomplish this several unique design techniques are utilized.

The first problem to be overcome is the settling time of the input multiplexer. This problem is solved by utilizing a "pre-charge" technique. As shown below, a unity gain instrumentation amplifier is used to settle the mux to within a few percent of its final value. Prior to sample capture, the "pre-charge" amp is disconnected and the mux allowed to complete accurate settling using the precision matched passive multiplexer.

The second problem to overcome is the programmable gain amplifier. The major task is to design an amplifier which will slew and settle quickly while maintaining the offset performance characteristics usually found in lower speed precision instrumentation amplifiers. The solution applied here is the use of a "composite" amplifier. This solution, as depicted below, utilizes a low offset/low drift amplifier to set the offset compensation of the high speed amplifier. 


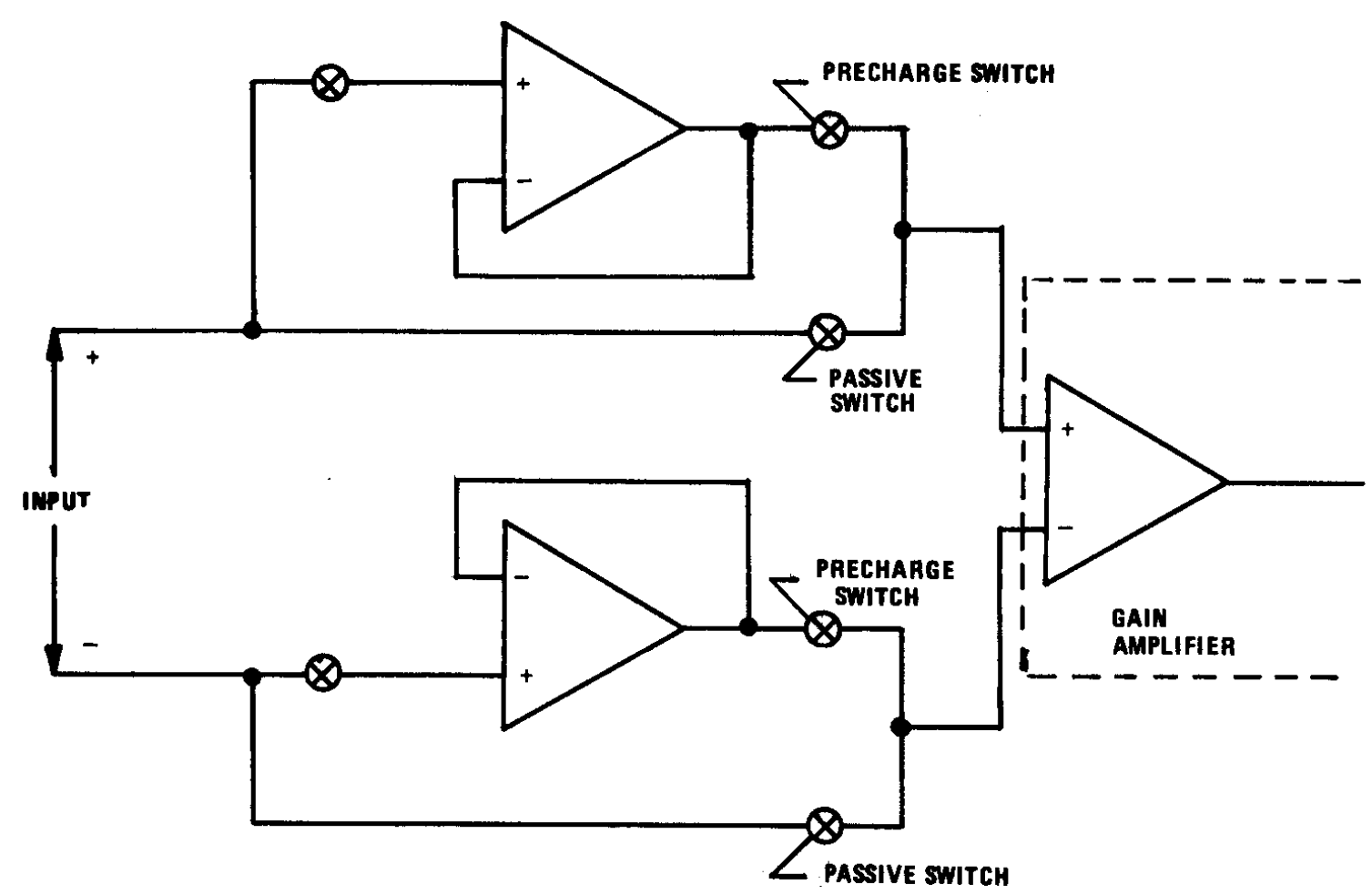

PRECHARGE MUX

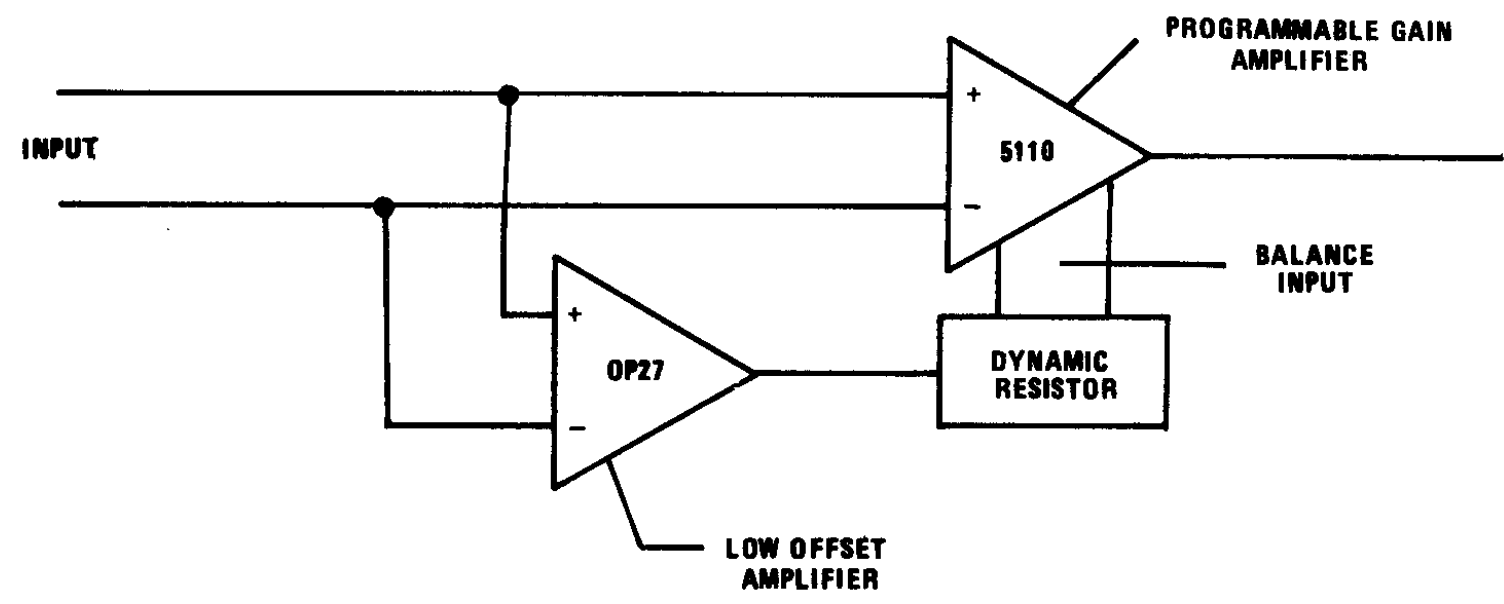

COMPOSITE AMPLIFIER

The last major hurdle is to allow sufficient time for the conversion of the analog data to digital form. This is accomplished by the utilization of dual track and hold circuits. While one circuit is holding data for A/D conversion, the second is connected to the composite amplifier output taking a sample for the next digital conversion. The general performance characteristics of the ADAU are: 


$\begin{array}{ll}\text { Processor } & - \text { N/A } \\ \text { Direct Input MUX } & -32 \text { Differential Channels } \\ \text { Sample Rate } & -400 \mathrm{~K} \text { Samples/Second } \\ \text { Input Range } & - \pm 10 \text { Volts } \\ \text { Digital Conversion } & -12 \mathrm{Bit} \\ \text { Accuracy } & -.2 \text { to } .5 \% \text { depending on range) } \\ \text { Gain } & -1 \text { to } 1000 \text { Programmable } \\ \text { Operating Temperature } & --54^{\circ} \text { to }+85^{\circ} \mathrm{C}\end{array}$

\section{SIGNAL CONDITIONING}

As discussed previously, the AFFTIS signal conditioning has been designed to provide maximum flexibility. The signal conditioning cards go into one of six slots within the ADAU housing. Listed below are the Signal Conditioners currently being developed:

\begin{tabular}{|c|c|}
\hline Resistance Thermometer & $\begin{array}{l}\text { - Programmable Constant Current } \\
.2 \text { to 5MA - } 8 \text { Channels }\end{array}$ \\
\hline Synchro/Resolver & - 11.8V \& 90V - 2 Channels \\
\hline Frequency Converter & $\begin{array}{l}-5 \mathrm{~Hz} \text { to } 50 \mathrm{~Hz} / 5 \mathrm{Mv} \text { to } 100 \mathrm{v} \\
4 \text { Channels }\end{array}$ \\
\hline Pulse Accumulator & $-5 \mathrm{~Hz}$ to $50 \mathrm{~Hz} / 5 \mathrm{Mv}$ to $100 \mathrm{v}$ \\
\hline Elapsed Time Counter & $\begin{array}{l}-.01 \text { Msec Resolution } \\
6 \text { Channels }\end{array}$ \\
\hline Serial Digital & - 4 to 30 Bits - 4 Channels \\
\hline Parallel Digital & $\begin{array}{l}\text { - } 16 \text { Bit/Isolated Input } \\
1 \text { Channel }\end{array}$ \\
\hline Analog Attenuator & - 1 to $1 / 32-8$ Channels \\
\hline Control Signal Generator & - 4 Outputs/TTL \& Relay Closure \\
\hline Presample Data Filters & - $2 \mathrm{~Hz}$ to $2 \mathrm{KHz}-4$ Channels \\
\hline Linear Variable/ & - $400 \mathrm{~Hz}$ to $2.5 \mathrm{KHz} / 2 \mathrm{VRMS}$ to $10 \mathrm{VRMS}$ \\
\hline Differential Transformer & 3 Channels \\
\hline Transducer Ref. Supply & $- \pm 2.5 / 5 / 10 \mathrm{~V}-4(+) \& 4(-)$ Channels \\
\hline
\end{tabular}

The Signal Conditioners are designed with many user definable options. Virtually all of these options can be programmed via the AFFTIS Ground Support Equipment without removal from the aircraft.

\section{GROUND SUPPORT EQUIPMENT}

In order to provide the user the support necessary to easily handle the programmability and checkout of the airborne hardware, the AFFTIS system includes a full spectrum of Ground 
Support Equipment. This equipment ranges from a multi-user Laboratory Support System with a complement of automatic test equipment to a hand-held Portable Flightline Unit (PFU) used for a singlechannel decom.

The AFFTIS GSE includes both general purpose and specific equipment. The general purpose GSE includes:

\begin{tabular}{lll}
\multicolumn{1}{c}{$\underline{\text { Unit }}$} & $\underline{\text { ID }}$ & $\underline{\text { Usage }}$ \\
Laboratory Support System & LSS & Laboratory \\
Ground Support Unit & GSU & Tow Cart \\
Remote Site Unit & RSU & Hand Carry
\end{tabular}

The general purpose GSE is designed utilizing standard equipment and software which enhances its ability to be tailored to each user's specific requirements.

$\underline{\text { Hardware }}$

Motorola 68000

VNE Bus

3-10 MByte Disks $\underline{\text { Software }}$

UNIX (tm)

ADA (tm)

Relational DBMS

This complement of hardware and software is maintained throughout the general purpose GSE thereby enhancing the ease of use and maintainability.

\section{LABORATORY SUPPORT SYSTEM}

The Laboratory Support System is a computer-based set of equipment that provides complete support of the airborne system to include (1) conduct of Acceptance Test Procedures; (2) generation of airborne formats; (3) PCM quicklook display and (4) engineering unit conversion. As a multi-user station, the LSS will conduct several different activities simultaneously. Designed as a "user-friendly" system, the LSS will automatically account for formatting requirements, evaluation of test results, and performance of PCM data limit checking. Automatic test of the airborne equipment is facilitated by a set of IEEE-488 standard lab test gear.

The LSS also serves as a software development facility for the GSE. Based on the UNIX (trademark Bell Labs) operating system, the GSE provides an ADA language compiler and a relational data base management system. The AFFTIS system user may develop and add his own software to the standard package. 


\section{GROUND SUPPORT UNIT}

The Ground Support Unit (GSU) is a mobile subset of the LSS functionality. Enclosed in a wheeled tow cart, the GSU provides the complete capability of the LSS except that it cannot perform airborne unit acceptance tests, or shop-level diagnostics. The GSU cart may be transported by air if necessary. Since the GSU is used in a wide variety of environmental extremes, a special terminal based upon a plasma display device is used instead of a traditional CRT. Extra rack space is available for the installation of missionspecific customer equipment. The GSU may be powered either from a standard aircraft power cart or commercial power.

\section{REMOTE SITE UNIT}

Where it is inconvenient to use a GSU, the Remote Site Unit will perform the equivalent functions of a GSU. Instead of a cart, the RSU is packaged in a man portable container. Like the GSU; the RSU uses a plasma terminal for its operator interface. The RSU may be powered from 110 volts from $47 \mathrm{~Hz}$ to $440 \mathrm{~Hz}$.

The characteristics of the General Purpose GSE are shown in Table 1.

\section{SPECIFIC GSE}

Other ancillary ground equipment comprises the Specific Category. This includes:

$\begin{array}{lll}\text { Party Line Decom } & \text { - PLD } & \text { AFFTIS Bus Decom and Test } \\ \text { Time Code Head } & \text { - TCH } & \begin{array}{l}\text { Time Code Generator Display and Set } \\ \text { Load, verify and dump of airborne } \\ \text { Portable Memory Loader }\end{array} \\ \text { - PML } & \text { memories without using LSS, GSU, RSU } \\ \text { Portable Flightline Unit } & \text { - PFU } & \begin{array}{l}\text { Single-channel raw data decom in a } \\ \text { hand-held unit. }\end{array}\end{array}$

\section{PROGRAM SCHEDULE}

Shown below is the overall development program schedule. As can be seen, the conceptual design phase is essentially complete and the Engineering Model development is underway. The System is scheduled to be ready for operational application by the end of CY 1986. 


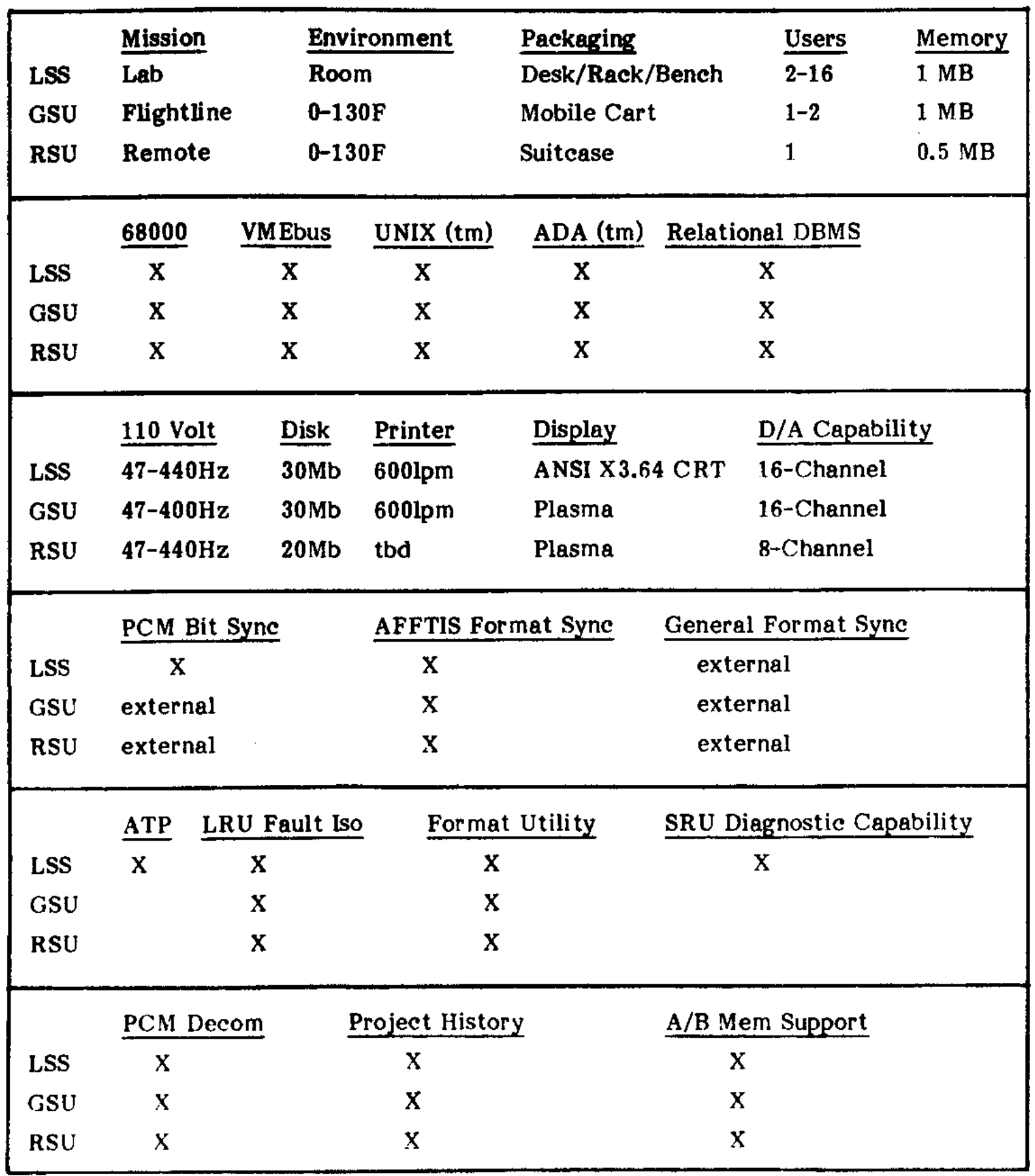

TABLE 1 
AFFTIS PROGRAM SCHEDULE

\begin{tabular}{|c|c|c|c|c|c|}
\hline & 1983 & 1984 & 1985 & 1986 & 1987 \\
\hline QTR & $\begin{array}{llll}1 & 2 & 3 & 4 \\
\end{array}$ & 1234 & $\begin{array}{llll}1 & 2 & 3 & 4 \\
\end{array}$ & 1234 & 1234 \\
\hline \multicolumn{6}{|l|}{$\begin{array}{l}\text { PHASE } 1 \\
\text { DESIGN }\end{array}$} \\
\hline \multicolumn{6}{|l|}{$\begin{array}{c}\text { PHASE } 2 \\
\text { EM DEVELOPMENT }\end{array}$} \\
\hline \multicolumn{6}{|l|}{$\begin{array}{c}\text { PHASE } 3 \\
\text { PRE PRODUCTION }\end{array}$} \\
\hline $\begin{array}{l}\text { PROGRAM } \\
\text { MILESTONES }\end{array}$ & & $\begin{array}{l}\mathrm{PDR} \\
2 / 15 \\
\end{array}$ & $\begin{array}{l}\text { CDR } \\
1 / 15 \\
\end{array}$ & $\begin{array}{|lr|}\text { FLT TEST } & \text { IOC } \\
\mathbf{A} & \mathbf{\Delta} \\
1 / 31 & 10 / 30 \\
\end{array}$ & \\
\hline $\begin{array}{l}\text { HARDWARE } \\
\text { DELIVERIES }\end{array}$ & & & EM & PRE PF & DDUCTION \\
\hline
\end{tabular}

\section{SUMMARY AND CONCLUSIONS}

In conclusion, the AFFTIS development is very ambitious and has demanded a lot of innovative design to accomplish. Any design which is meant to serve many applications must have built in a high degree of flexibility to allow the tailoring needed to meet specific applications.

The AFFTIS design is meeting these goals. 